\title{
Processos de gestão na educação a distância: análise da coordenação de polo no
} sistema Universidade Aberta do Brasil

\author{
Management processes in distance education: analysis of the polo coordination in the Open \\ University of Brazil system \\ Procesos de gestión en educación a distancia: análisis de la coordinación polo en el sistema Abierto \\ de la Universidad de Brasil
}

\section{Resumo}

Esse estudo busca compreender os processos de gestão de polos da Universidade Federal de Santa Maria (UFSM), no âmbito da Universidade Aberta do Brasil (UAB) considerando as políticas públicas que organizam a UAB e seus desdobramentos. A pesquisa foi desenvolvida no Programa de Pós-Graduação em Políticas Públicas e Gestão Educacional. O aporte teórico fundamentou-se nos principais autores que pensam as políticas públicas para Educação a Distância (EaD) no Brasil e sobre os processos de gestão educacional. Buscou-se no balizamento legal a regulamentação da UAB procurando elementos que configurem a atuação do Coordenador de Polo nesse cenário. Os encaminhamentos metodológicos baseiam-se na abordagem qualitativa, ao considerar que o pesquisador não fica fora da realidade que estuda, à margem dela, dos fenômenos aos quais procura compreender seus significados. Como sujeitos da pesquisa definiram-se seis coordenadoras de polos com oferta ativa do Curso de Pedagogia da UAB/UFSM. A coleta de dados se deu através de entrevistas semiestruturadas, realizadas tanto presencialmente, quanto a distância. Para analisar os dados, utilizou-se a Análise Textual Discursiva. A partir das análises surgiram três categorias: $1^{\mathrm{a}}$ ) $\mathrm{O}$ processo de escolha do coordenador de polo; $2^{\mathrm{a}}$ ) As percepções acerca das atribuições do coordenador de polo; $3^{\mathrm{a}}$ ) As dificuldades vivenciadas como coordenadora de polo. Ao finalizar a pesquisa, observouse que um conhecimento mais detalhado dos documentos e materiais descritores das atividades que compõem seu trabalho poderiam qualificar a gestão dos coordenadores no polo.

Palavras-chave: Políticas públicas; Gestão de polos; Ensino superior.

\begin{abstract}
This study seeks to understand the pole management processes of the Federal University of Santa Maria (UFSM), within the scope of the Open University of Brazil (UAB) considering the public policies that organize the UAB and its developments. The research was developed in the Postgraduate Program in Public Policies and Educational Management. The theoretical contribution was based on the main authors who think public policies for Distance Education (EAD) in Brazil and on the educational management processes. The UAB regulation was sought in the legal framework, looking for elements that configure the Pole Coordinator's performance in this scenario. The methodological guidelines are based on the qualitative approach, considering that the researcher is not outside the reality he studies, outside of it, of the phenomena to which he seeks to understand their meanings. Six research coordinators were defined as research subjects with active offer of the Pedagogy Course at UAB / UFSM. Data collection took place through semi-structured interviews, carried out both in person and at a distance. To analyze the data, Discursive Textual Analysis was used. Three categories emerged from the analyzes: 1st) The process of choosing the pole coordinator; 2nd) Perceptions about the pole coordinator's duties; 3rd) The difficulties experienced as a pole coordinator. At the end of the research, it was observed that a more detailed knowledge of the documents
\end{abstract}


and materials describing the activities that make up his work could qualify the management of the coordinators at the pole.

Keywords: Public policy; Pole management; University educacion.

\section{Resumen}

Este estudio busca comprender los procesos de gestión de polos de la Universidad Federal de Santa María (UFSM), en el ámbito de la Universidad Abierta de Brasil (UAB) considerando las políticas públicas que organizan la UAB y sus desarrollos. La investigación se desarrolló en el Programa de Posgrado en Políticas Públicas y Gestión Educativa. El aporte teórico se basó en los principales autores que opinan las políticas públicas de Educación a Distancia (EAD) en Brasil y en los procesos de gestión educativa. Se buscó la regulación de la UAB en el marco legal, buscando elementos que configuren el desempeño de la Coordinadora de Polo en este escenario. Los lineamientos metodológicos se basan en el enfoque cualitativo, considerando que el investigador no está fuera de la realidad que estudia, fuera de ella, de los fenómenos a los que busca comprender sus significados. Se definieron seis coordinadores de investigación como sujetos de investigación con oferta activa en el Curso de Pedagogía de la UAB/UFSM. La recolección de datos se realizó a través de entrevistas semiestructuradas, realizadas tanto en persona como a distancia. Para el análisis de los datos se utilizó el Análisis Textual Discursivo. De los análisis surgieron tres categorías: 1) El proceso de elección del coordinador del polo; $2^{\circ}$ ) Percepciones sobre las funciones del coordinador de polo; $3^{\circ}$ ) Las dificultades vividas como coordinador de polos. Al final de la investigación, se observó que un conocimiento más detallado de los documentos y materiales que describen las actividades que componen su trabajo podría calificar la gestión de los coordinadores en el polo.

Palabras clave: Políticas públicas; Gestión de polos; Ensenãnza superior.

\section{Introdução}

O presente artigo contempla a possibilidade de novos olhares para a gestão dos polos de apoio presencial da Universidade Aberta do Brasil (UAB), evidenciando os resultados obtidos em pesquisa desenvolvida no Programa de PósGraduação em Políticas Públicas e Gestão Educacional da Universidade Federal de Santa Maria (UFSM). O estudo apresenta a relevância do papel do coordenador de polo no contexto da UAB como política educacional de formação e qualificação de professores da educação básica.

Ao considerar a gestão do polo como foco do estudo, elegemos como sujeito da pesquisa o coordenador do polo de apoio presencial UAB. Entendemos que, devido às suas atribuições como gestor administrativo e pedagógico, ele é o principal articulador dos processos de gestão ali estabelecidos. Além disso, esse sujeito tem responsabilidade no que se refere às questões de implantação, desenvolvimento, consolidação, crescimento e intermediações das instituições de ensino superior com o mantenedor municipal.

O polo de apoio presencial facilita e propicia que o ensino público, gratuito e de qualidade alcance os mais diferentes lugares, por meio das tecnologias educacionais viabilizadas pela internet. Essas potencialidades se tornam ainda mais eficazes quando as estruturas contam com uma eficiente equipe gestora.

A figura do coordenador de polo é foco central neste estudo que se justifica por acreditarmos ser um profissional fundamental no polo UAB, e que apresenta características específicas de gestão, e estas devem atender as normativas definidas pela Coordenação de Aperfeiçoamento de Pessoal de Nível Superior - CAPES.

Assim, esta investigação priorizou compreender os processos de gestão de polos vinculados a Universidade Aberta do Brasil, considerando as políticas públicas, o processo de seleção, as atribuições e o perfil do coordenador de polo com vistas à qualificação de sua atuação profissional.

\section{Aportes Teóricos do Estudo Sobre Gestão e Coordenação de Polo}

Mediante o contexto de contemporaneidade que vem sendo dado à Educação a Distância (EaD), cabe esclarecer que segundo Moore (2010) ela vem sendo classificada por gerações que se inicia no começo dos anos 80 , com o estudo por correspondência, classificada como a primeira geração, com o estudo em casa. $\mathrm{O}$ estudo em casa era favorecido por uma 
tecnologia; os serviços postais baratos e confiáveis, resultantes da expansão da malha ferroviária. Surgem as primeiras escolas tendo uma visão lucrativa desta modalidade de ensino, sendo que o estudo independe das universidades para que isto aconteça. A segunda geração foi o ensino por meio da difusão do rádio e pela televisão. E a terceira geração é marcada pela invenção de uma nova modalidade de educação, notável nas universidades abertas. A quarta geração é a teleconferência baseada na tecnologia da teleconferência sendo pensada para o uso em grupo. A quinta geração recebe aulas virtuais baseadas no computador e na internet.

Este contexto de expansão e crescimento coincide com a aprovação do Decreto 5.622, de 19 de dezembro de 2005, que regulamenta o Artigo 80 da Lei de Diretrizes e Bases (LDB) (Brasil, 1996):

Art. $1^{\circ}$. Para os fins deste Decreto, caracteriza-se a Educação a Distância como modalidade educacional na qual a mediação didático-pedagógica nos processos de ensino e aprendizagem ocorre com a utilização de meios e tecnologias de informação e comunicação, com estudantes e professores desenvolvendo atividades educativas em lugares ou tempos diversos (Brasil, 2005).

Aprovada a EaD como modalidade de ensino, com reconhecida mediação didático-pedagógica pelo decreto citado, através da utilização das tecnologias de informação e comunicação para as atividades educacionais, a UAB é oficializada pelo Decreto 5.800, de 18 de junho de 2006 (Brasil, 2006).

$\mathrm{O}$ cenário do surgimento da $\mathrm{UAB}$ é marcado pela importância que a modalidade a distância representa frente à crescente demanda por formação superior no contexto nacional. Esta demanda propiciou uma parceria entre o governo federal, estadual e municipal, com a dinâmica de implantação dos polos como espaços acadêmicos de apoio pedagógico, tecnológico e administrativo para as atividades de ensino- aprendizagem dos cursos e programas de Educação a Distância ofertados pela $\mathrm{UAB}$.

Para o funcionamento dos cursos, há a necessidade de uma unidade operacional com mobiliários e condições adequadas, de conforto no ambiente de estudo, boa iluminação, acústica e ventilação, bem como a composição de uma equipe da UAB para atender presencialmente àqueles que procurassem estes espaços denominados Polos de Apoio Presencial. O processo de gestão de polos de apoio presencial está atrelado a um "fazer EAD" que preconiza as práticas vivenciadas nesta modalidade de ensino, assim, as teorias de administração estão voltadas à contingência estrutural do mesmo.

O contexto organizacional de um polo de apoio presencial de acordo com Carrieri et al. (2008), necessita passar pelo entendimento do conceito de gestão. Sendo entendido como um fazer cotidiano, associado a contextos micro e macrossociais que se limitam às organizações. A organização exerce um papel fundamental, pois auxiliam no desenvolvimento dos cursos, e servem de referência para os estudantes que lá frequentam.

Segundo Lima (2014), a gestão deve ser democrática observando os novos modelos que se constituem, sem deixar de valorizar os antigos modelos, sem perder o foco da organização em si. Conforme o autor, várias são as formas de gestão, mas o gestor deve ter a visão de sua organização envolvendo seus relacionamentos, para gerir o presente e projetar o futuro vislumbrando crescimento e expansão.

Ao reportar esta realidade de gestão para o ambiente do polo de apoio presencial, é preciso considerar que, mesmo direcionado por um órgão maior como o MEC, as ações do gestor se contextualizam frente a diferentes realidades, no contexto de estudantes, e, também, subjugado ao gestor municipal, uma vez que o mesmo pode mudar a cada quatro anos.

Conforme Vargas, Lima e Azevedo (2011), o coordenador de polo que exercendo a função de gestor, dentre as atividades que realiza, ainda apresenta uma função social. Destacam que além de ser um espaço acadêmico, voltado para aprendizagens, o polo é um lugar que necessita de um gestor que tenha sensibilidade para identificar as necessidades, 
prioridades e demandas do que é relevante para a comunidade. O polo é um espaço acadêmico que agrega valor à comunidade em que está inserido (Vargas, Lima, \& Azevedo, 2011).

$\mathrm{O}$ profissional indicado para a coordenação de polo precisa atender aos requisitos no que diz respeito à formação acadêmica de nível superior, e experiência docente na educação básica ou no ensino superior de no mínimo três anos. Para os profissionais que irão atuar no polo, a UAB oferece bolsas aos coordenadores e aos tutores presenciais, ficando os demais componentes da equipe a cargo do governo municipal, mantenedor do mesmo.

Em uma tentativa de estabelecer referenciais de qualidade para a gestão de polos no sistema Universidade Aberta do Brasil, Silva et al. (2010) destaca as atribuições e competências de um coordenador de polo como um elemento fundamental na estrutura de EaD. O artigo propõe clareza ao descrever os diversos fatores estruturais e organizacionais essenciais ao papel do coordenador do polo, esclarecendo que este deverá ter uma ampla visão e domínio sobre sua gestão, garantindo o bom funcionamento do polo.

Ao dissertar sobre as alternativas de financiamento, a partir da análise da gestão de polos de municípios do estado do Espírito Santo, Bossato et. al. (2017) faz uma análise baseada na legislação do tema, propondo alterações. A relevância do estudo está na necessidade apontada de conhecer e descrever a receptividade dos coordenadores de polo em relação às parcerias, analisando o sistema que monitora e a qualidade da infraestrutura para indicar suas fragilidades.

As contribuições destas leituras possibilitaram o entendimento de que a atuação do gestor deve ser de comprometimento pessoal e que suas ações devem ser amparadas no trabalho colaborativo. Para Almeida (2003), ações estabelecidas em conjunto com os pares, com a competência de resolver problemas em grupo, com autonomia ao fazer e ao compreender. Neste sentido, as informações são selecionadas, organizadas e contextualizadas segundo as expectativas do grupo, permitindo que este estabeleça múltiplas relações, retroações e recursões, e a partir destas atribuindo-lhes um novo sentido que ultrapassa a compreensão individual.

O coordenador é a principal ligação entre o polo, as Instituições de Ensino Superior e o poder público municipal, estando atento às demandas de cursos, ofertas de novos cursos e reedições ofertadas. Além disto, é responsável pela observação das demandas que devem ser supridas pelo mantenedor do polo.

No contexto de coordenação conforme Oliveira (2007) é fundamental criar mecanismos para planejar, capacitar e controlar as atividades desenvolvidas entendidas como elemento basilar para que as organizações atinjam seus objetivos. As atividades pedagógicas que permeiam a relação professor/tutor/estudante também devem passar pelo olhar atento e criterioso do coordenador. Nesse sentido, Lück (2001, p.1) esclarece que "o conceito de gestão está associado ao "fortalecimento da democratização do processo pedagógico, à participação responsável de todos nas decisões necessárias e na sua efetivação mediante um compromisso coletivo com resultados educacionais cada vez mais efetivos e significativos".

A gestão educacional entendida como um processo coletivo de planejamento, organização e desenvolvimento de um projeto político-pedagógico, representa um novo modelo na educação. Nesse cenário, surgem novas ideias e orientações a partir da compreensão da rede de relações que se estabelecem no contexto educacional. Assim, esse coordenador de polo deverá deter conhecimento do que diz o projeto político pedagógico de cada curso que o polo acolhe, auxiliando acadêmicos, tutores e quem procura informações solucionando possíveis dúvidas. No polo de educação a distância, a relação a distância é mediada e diminuída pelo Ambiente Virtual de Aprendizagem (AVA), necessitando do envolvimento de toda a equipe, em um primeiro contato apresenta complexidade ao acadêmico, que recebe orientação, minimiza e acaba com o passar do tempo.

Portanto, o enfoque da gestão fundamentado no diálogo e participação pode superar a visão educacional singular e simplista e passa abranger um conjunto de responsabilidades de ordem pedagógica, da organização e da funcionalidade da educação. 


\section{Amparo Metodológico da Pesquisa}

A partir das questões previamente estabelecidas foram definidas as ações a serem realizadas para alcançar os objetivos propostos para o estudo. Então, nos amparamos em Minayo (2009), para esclarecer que:

Entendemos por metodologia o caminho do pensamento e a prática exercida na abordagem da realidade. Ou seja, a metodologia inclui simultaneamente a teoria (o método), os instrumentos de operacionalização do conhecimento (as técnicas) e a criatividade do pesquisador (sua experiência, sua capacidade pessoal e sua sensibilidade) (Minayo, 2009, p.14).

Para atingir os objetivos definidos optamos por uma metodologia que abarcou as questões levantadas, buscando soluções, uma vez que esta é a ordenação do pensamento na realidade vivenciada no contexto da pesquisa. As ideias centrais que orientam a metodologia deste estudo caracterizam-se como pesquisa qualitativa, por convergirem com os objetivos propostos de valorização da visão dos sujeitos envolvidos na pesquisa e na visão do pesquisador.

$\mathrm{O}$ estudo foi realizado com seis gestoras de polos de apoio presencial da UAB, que ofertam o curso de Pedagogia da UAB/UFSM. Foram realizadas entrevistas, sendo que duas delas foram in loco, a qual favoreceu a observação da gestão de pessoal, estrutura física, acolhida a acadêmicos e visitantes, o que foi viabilizado em dois polos. As outras quatro foram realizadas a distância, utilizado recursos como Google Meet e WattsApp.

Como metodologia de tratamento dos dados, utilizamos a Análise Textual Discursiva (ATD), proposta por Moraes e Galiazzi (2007). Emergiram das entrevistas, três categorias a serem analisadas a partir dos objetivos da pesquisa. A primeira categoria prioriza o processo de escolha do coordenador de polo. Na sequência, emerge as percepções deste coordenador na gestão, antes e depois de assumir as funções de gestor. Finalizando, a terceira categoria surge com as dificuldades apontadas na execução das atividades cotidianas.

A partir do processo de análise por categorias, evidenciamos respostas aos objetivos que propusemos e, assim, contemplar de forma satisfatória a confecção do tutorial, tendo por base os anseios vividos no cotidiano do coordenador de polo, uma vez que este segue a estruturação de temas definidos nas categorias geradas pelas entrevistas.

Assim, o 'corpus' que compõe a análise parte de seis entrevistas com as coordenadoras de polo da UAB que recebem o Curso de Pedagogia da UFSM, sendo três coordenadoras de polo com maior tempo de gestão, e três coordenadoras com menor tempo.

As categorias emergentes foram: Processo de escolha do coordenador de polo; Percepções acerca das atribuições do coordenador de polo e dificuldades vivenciadas como coordenador de polo.

\section{Significados que Emergiram do corpus da Pesquisa}

Para abordar o processo de gestão, buscamos amparo em Figueiredo (2017), o qual sobreleva as formas de gestão ou administração, reportando que esta não deve ser estática, mas evolutiva, de forma que todos possam contribuir com seu modo de pensar. Assim, o gestor da atualidade não pode se limitar a supervisionar e controlar, mas orientar e projetar de modo colaborativo. Nesse contexto organizacional, a equipe de colaboradores tem uma ampla visão da organização, com objetivos definidos para que se alcance dinamismo e flexibilidade das organizações. Dessa forma, planejar consiste em organizar a própria ação, dando clareza e fundamento ao conjunto de práticas, isto é, planejar é imprescindível.

De acordo com Lück (2001), os sistemas educacionais e os estabelecimentos de ensino, como unidades sociais, são organismos vivos e dinâmicos, e como tal devem ser entendidos. A gestão educacional tenta, ao longo do processo, responder a caracterização de uma rede de relações entre fatores que interferem direta ou indiretamente, por isso se faz necessário um novo olhar para a organização. Tendo como foco a prática social, a gestão se torna um meio orientador de ações diretivas para a 
execução e organização da aprendizagem, com o intuito de gerir e solucionar os anseios sociais que demandam do seu contexto.

A reflexão a respeito da gestão democrática e sua responsabilidade social elucidaram a organização e sistematização dos dados coletados nas entrevistas, e, a partir disso, elegemos três categorias para dar conta do que se propõe.

\subsection{Processo de escolha da coordenação de polo}

O processo de escolha para a gestão da função de coordenador de polo do Sistema UAB apresenta características próprias. Para tanto é relevante considerar que este gestor estará à frente da tomada de decisões, e, a partir disso, haverá a definição do crescimento ou não da instituição a qual está vinculado.

O professor coordenador de polo deverá desenvolver atividades relativas ao que normatiza o Art. $3^{\circ}$, Item III, Alínea “a” da Portaria CAPES n ${ }^{\circ} 183$, de 21 de outubro de 2016 do site no qual regulamenta as diretrizes para concessão e pagamento de bolsas aos participantes, preparação e execução dos cursos e programas de formação superior, inicial e continuada no âmbito do Sistema UAB (Brasil, 2016). Dentre elas, destacamos o inciso VI, que estipula o valor da bolsa do coordenador de polo e também determina que estes deverão exercer atividades de coordenação e supervisão de infraestrutura a ser disponibilizada em perfeitas condições de uso para viabilizar atividades realizadas no âmbito do polo, sendo exigida a condição de discente da Educação Básica com, no mínimo,1 (um) ano de experiência no magistério e formação de nível superior.

Atualmente, a Portaria 249 de 8 de novembro de 2018 regulamenta o Art. $7^{\circ}$ da Portaria CAPES no 183 de 21 de outubro de 2016 (Brasil, 2018), a qual prevê a possibilidade de realização de um processo seletivo para a escolha do coordenador de polo, mantendo a qualificação exigida para a ocupação do cargo.

É preciso compreendermos esse sujeito que assume a coordenação do polo como alguém que enfrenta algo totalmente novo. Ele vem de uma realidade da educação básica e, mesmo que conheça os meandros da gestão, da administração de uma escola, por exemplo, desconhece e/ou pouco conhece, as demandas do ensino superior e da modalidade a distância. Observa-se que, ao assumirem o cargo, as entrevistadas não tinham muito conhecimento do que implicava "ser uma coordenadora de polo", principalmente porque a gestão de um polo pressupõe uma série de tessituras entre os anseios da comunidade e os trâmites legais que o ensino superior demanda para a implantação e permanência de cursos superiores na modalidade a distância.

$\mathrm{Na}$ construção da pesquisa buscamos compreender os caminhos trilhados por uma das coordenadoras que preenchia as exigências da função, e que foi uma das principais responsáveis pelo processo de implantação do polo da Universidade Aberta do Brasil em seu município. A mesma relata que a primeira iniciativa do Governo Federal foi explicar e orientar as ações de implantação da educação a distância nos municípios. Descrevendo sua vivência, compreendemos as dificuldades, desafios e busca por soluções enfrentadas:

Muitas dificuldades, mas mais dúvidas e incertezas, porque nós recebemos capacitação em Brasília, recebemos as primeiras orientações da CAPES, mas para a implantação do projeto mesmo. Fomos chamados a Brasília, e lá foinos apresentado o que estava sendo previsto no programa Universidade Aberta do Brasil, e o que nós faríamos neste contexto. A gente sabia nossas incumbências, mas também depois, na hora de executar, muitas dúvidas. Eu criei um plano de gestão do polo, onde todos os anos a gente coloca no papel as prioridades, daquele ano, os cursos daquele ano, o que de diferente a gente vai proporcionar, para a comunidade. Como por exemplo de abrir o polo para integrar a comunidade, no plano de gestão a CAPES sugeriu, mas nunca existiu um modelo, regimento da biblioteca, regimento do polo, conselho do polo, todos estes documentos eu elaborei aqui em conjunto com a minha equipe, e nós 
não tínhamos noção do que exatamente deveria constar no regimento do polo para o bom andamento. (Coordenadora Nina ${ }^{l}$ )

Nesse primeiro momento de formação propiciado pela CAPES, as coordenadoras tiveram o entendimento sobre o que o Governo Federal estava propondo, e as diretrizes que o Sistema Universidade Aberta do Brasil adotaria para expandir e interiorizar a oferta de cursos e programas voltados à educação superior. Conforme a coordenadora: "Foi-nos apresentado o que deveria ser realizado em cada município que acolheria o sistema" conclui ela. Mas a delimitação das ações que deveriam ser implantadas, os caminhos percorridos para implantar, alcançar e consolidar os objetivos propostos dependeria da visão de coordenação da pessoa que estava assumindo.

Ao entendermos a professora que vem da educação básica como uma nova gestora, o de coordenadora do polo de apoio presencial que acolhe o ensino superior na modalidade a distância, observamos que as mesmas não possuíam preparo prático e teórico a respeito do que seria uma gestão democrática com vistas ao ensino superior.

\subsection{Percepções acerca das atribuições da coordenação de polo}

Ao assumir a coordenação de um polo de apoio presencial, surgem múltiplos desafios, vistos pela perspectiva de algumas entrevistadas, como algo a ser encarado de forma muito solitária. É o momento de compreender as atribuições, definir planos para a gestão de um sistema que, por ser de ensino superior e, ainda mais na modalidade a distância, tem suas peculiaridades. Além disto, existem as obrigações com a comunidade, porque ali deve estar à qualificação dos munícipes, e contemplar anseios da gestão municipal com ações efetivas.

Para a professora que sai da educação básica para assumir essa função é diferente, e, porque não dizer, assustador, pois chega com vivências de um modelo de educação básica que não contempla as necessidades de um ensino superior a distância.

Temos como exemplo o fato de acolher um processo de seleção para ingresso num curso de graduação, pósgraduação, qualificação, confirmação de vagas, matrículas, avaliações online, entre outras possibilidades do que é enfrentado. Podemos evidenciar essas questões na fala a seguir:

Eu sou coordenadora, eu preciso articular perante as universidades, perante as coordenações de cursos, perante os alunos, para a efetivação do estudo para que realmente aconteça, para que não haja desistência, a gente está sempre na organização do polo, atrás de cursos, mantendo a universidade viva no polo. Além da gestão a gente faz a articulação e toda a parte de documentos, a gente não tem secretária, então a gente faz isso também. (Coordenadora Bela)

No decorrer das entrevistas, percebemos que todas apresentam uma preocupação com o desenvolvimento de seu polo, e buscam soluções e alternativas que contemplem as o atendimento dessas demandas. No processo de constituição, enquanto gestoras entendem que representam o elo entre as administrações, mantenedor municipal e universidades, bem como com as demais unidades, equipe administrativa e pedagógica, que proporcionam a efetiva execução das políticas, metas e objetivos.

\footnotetext{
1 Ao reportarmos o nome das coordenadoras e as falas destas, estaremos destacando em itálico.
} 


\subsection{Fragilidades vivenciadas pela coordenação de polo}

Até o final de 2016, vínhamos em um processo de crescimento com significativos resultados na formação e qualificação de profissionais nas diferentes áreas do conhecimento. Atualmente, este panorama mudou bastante, e a preocupação das entrevistadas neste estudo diz respeito à ausência de oferta de novos cursos, reedições, cursos de aperfeiçoamento, aliados à falta de renovação dos apoios tecnológicos e acervo bibliográfico, entre outras solicitações.

Entretanto, temos a percepção de que, tanto coordenadoras, quanto mantenedores, conforme os relatos que surgiram nas entrevistas, não estão preparados para vivenciar o atual capítulo de cortes de investimento nos diferentes níveis do ensino superior. As coordenadoras Maria e Rosa trazem a realidade vivenciada pela falta de renovação no aporte tecnológico e da incerteza de novos cursos, mas não apontam a preocupação com o possível encerramento do Sistema UAB:

Em dia de provas que o sistema cai, as máquinas não comportam, quando uma turma toda acessa o ambiente onde tenha prova on-line o sistema tranca, ou o aluno perde a prova, às vezes ele precisa fazer a mesma prova três vezes, então esta parte tecnológica eu acho que é a mais complicada. A gente gostaria que a oferta fosse maior, e que agora está sendo diminuída a oferta, e que a gente não consegue atender como gostaria a nossa demanda aqui da região. (Coordenadora Maria)

A contrapartida do governo federal principalmente para a gente repor o material de informática, na verdade um dos meus laboratórios eu não tenho mais, ele ultrapassou, e o outro o município pagou, eu fui várias vezes pedir para o prefeito, pedi da necessidade, então ele, o município deu. Porque o nosso laboratório, desde 2012 e o técnico vem tentando restaurar as máquinas, mas a modernidade, tudo muda tão rápido, a gente precisa modernizar. Então as minhas maiores dificuldades são essas, a falta de oferta, a demora na oferta, e a falta de infraestrutura que venha nos ajudar por parte do governo federal. (Coordenadora Rosa)

As dificuldades vivenciadas no setor tecnológico pelo desgaste em função do tempo, e a falta de renovação das mesmas, resultantes da ausência de investimento, seria solucionada com a perspectiva de oferta de cursos, justificam as coordenadoras. Sem perspectivas, elas se veem impotentes, sem argumentos que as ampare, e ao mesmo tempo sendo cobradas pela comunidade conforme relata a coordenadora Rosa: "diariamente as pessoas me procuram, procuram a gestão municipal pedindo cursos, informações. Este momento de parada de oferta de cursos tem me causado sofrimento, esta é a minha maior dificuldade". Este conflito é concluído pela mesma coordenadora quando argumenta: "eu acho que a dificuldade de todas nós coordenadoras é essa, nos vermos, melhor, estar nos nossos polos com um número cada vez menor de alunos, e a gente não consegue se planejar".

As inquietações e dificuldades manifestadas pelas coordenadoras reforçam as incertezas do sistema, geradas pela ausência de investimento nas políticas públicas educacionais voltadas à formação e atualização de cursos que vinham sendo ofertados. Podemos considerar que, apesar de vivenciarem tais dificuldades, as coordenadoras participantes desta pesquisa ainda acreditam em mudança. Todavia nem elas, nem os mantenedores deflagram ações de pressão e cobrança de resultados às instituições competentes.

\section{Considerações Finais}

Ao longo do desenvolvimento do estudo, destacamos nosso entendimento de um momento de incertezas na educação a distância através do Sistema Universidade Aberta do Brasil. O cenário da pesquisa apontava para o início de um processo seletivo de coordenadores de polo que busca estabelecer algum parâmetro legal a manutenção deste gestor no exercício de sua função. De outra ordem, os editais de fomento estão cada vez mais escassos, e a CAPES não tem promovido grandes articulações com as IES desde 2016. Isto coloca os gestores e os mantenedores em uma situação muito delicada, pois as estruturas físicas do polo existem e os munícipes sabem da importância da UAB para a comunidade como um todo, entendem a importância do ensino superior, querem cursos... 
Ao longo da pesquisa buscamos traçar o perfil de um profissional que assume uma função por indicação, e que, mesmo sendo por indicação, este gestor deve deter habilidades e competências que lhe qualificam a função, seguindo as orientações e definições normatizadas na forma da lei. O conjunto de obrigações, sem o devido amparo, somente com a indicação de atribuições é bastante desafiador, pois terá de se construir na educação a distância no município. Para alguns, pouca formação, escassa ou quase nada; para outros, nada. O que foi realizado ou está sendo realizado é fruto de suas vivências e, para alguns, o que lhe foi passado pelo antecessor. Essa realidade deverá mudar com o novo processo de seleção que vem sendo realizado, porque garante a continuidade do coordenador na função, viabilizando um trabalho que tem seguimento e certa liberdade de ações.

É possível considerar que as coordenadoras de polo ousaram, criaram, pesquisaram, fizeram acontecer durante seus períodos de gestão. Atualmente, não podemos vislumbrar certezas de crescimento e expansão pela ausência de investimento e incentivo de novas Políticas Públicas.

\section{Referências}

Almeida, M. E. B. (2003). Educação a distância na internet: abordagens e contribuições dos ambientes digitais de aprendizagem. Educação e Pesquisa, 29(2), $327-340$.

Bossato, J. P. et al. (2017). Gestão de polos municipais do sistema universidade aberta do Brasil: alternativas de financiamento-uma abordagem no estado do Espírito Santo. Dissertação de Mestrado. Universidade Federal do Espírito Santo.

Brasil (1996). Lei 9.394 de 1996. Estabelece as diretrizes e bases da educação nacional. Brasília, DF.

Brasil (2018). Ministério da Educação. Recuperado em 26 out. 2018, de http://www2.senado.leg.br/bdsf/bitstream/handle/id/70320/65.pdf.

Brasil (2005). Decreto $n^{\circ}$ 5.622, de 19 de dezembro de 2005. Regulamenta o art. 80 da Lei no 9.394, de 20 de dezembro de 1996 , que estabelece as diretrizes e bases da educação nacional. Brasília, DF: Presidência da República, 2005. http://portal.mec.gov.br/seed/arquivos/pdf/dec_5622.pdf

Brasil (2006). Decreto $n^{o}$. 5.800, de 08 de junho de 2006. Dispõe sobre o Sistema Universidade Aberta do Brasil - UAB. http://www.planalto.gov.br/c civil_03/_ato2004-2006/2006/decreto/d5800.htm

Brasil (2018). Portaria CAPES $n^{\circ}$ 249, de 8 de novembro de 2018. Coordenação de Aperfeiçoamento de Pessoal de Nível Superior. 2018, de https://www.capes.gov.br/images/stories/download/legislacao/12112018_PORTARIA_N\%C2\%BA_249_DE_8_DE_NOVEMBRO_DE_2018_.pdf.

Brasil (2016). Portaria CAPES no 183, de 21 de outubro de 2016. Coordenação de Aperfeiçoamento de Pessoal de Nível Superior. https://www.capes.gov.br/ im ages/stories/download/24-11-2017-Portaria-183-de-Bolsas-UAB.pdf.

Carrieri, A. P., Silva, A. R. L. \& Junquilho, G. S. (2008). O fazer estratégia na gestão como prática social: articulações entre representações sociais, estratégias e táticas cotidianas nas organizações. Anais da 32 ENANPAD.

Figueiredo, C. B. de. (2017). Educação a Distância: estudo da gestão de um polo de apoio presencial. 101f. Dissertação (Mestrado em Educação) Universidade do Oeste Paulista, Presidente Prudente.

Lima, L. C. (2014). A Gestão Democrática das Escolas: do autogoverno à ascensão de uma pós-democracia gestionária? Educação \& Sociedade, 35(129), 1067-1083. https://doi.org/10.1590/ES0101-73302014142170.

Lück, H. (2009). A Evolução da Gestão Educacional, a partir de Mudança Paradigmática. https://progestaoead.files.wordpress.com/2009/09/a-evolucao-dagestao-educacional-h-luck.pdf.

Minayo, M. C. de S. (2009). Trabalho de campo: contexto de observação, interação e descoberta. In. Minayo, M. C. de S., Deslandes, S. F. \& Gomes, R. (Org). (2009). Pesquisa social: teoria, método e criatividade (28a ed.) Vozes.

Moore, M. \& Kearsley, G. (2010). Educação a distância: uma visão integrada. Pearson Thomson Learning.

Moraes, R. \& Do Carmo Galiazzi, M. (2007). Análise textual: discursiva. Editora Unijuí.

Oliveira, D. P. R. (2007). Planejamento estratégico. Atlas.

Silva, E. R. G. da et al. (2010). Gestão de polo de apoio presencial no sistema Universidade Aberta do Brasil: construindo referenciais de qualidade. Renote, 8(3). https://seer.ufrgs.br/renote/article/view/18086/10662.

Vargas, J. E. N., Lima, R. S., \& Azevedo, H. H. D. (2011). Função social do gestor de polo no Sistema Universidade Aberta do Brasil. In: Anais do Congresso Nacional de Ambientes Hipermídia para Aprendizagem, Pelotas, RS. 